\title{
Commentary
}

\section{Implement of Face Recognition in Android Platform by Using Opencv and LBT Algorithm}

\author{
Liela Khobanizad $^{1}$, Mahmood Khobanizad ${ }^{2}$, Behrouz Vaseghi $^{2}$, Hamid Chegini $^{3}$ \\ ${ }^{1}$ Telecommunication of Non-profit Institution of Higher Education, ABA, Abyek, Qazvin, Iran \\ ${ }^{2}$ Electrical Engineering, Abhar Branch, Islamic Azad University, Abhar, Iran \\ ${ }^{3}$ Non-profit Institution of Higher Education, ABA, Abyek, Qazvin, Iran
}

\section{Email address:}

L.khoubani@yahoo.com (L. Khobanizad),mahmoodkhob@yahoo.com (M. Khobanizad), Behrouz.vaseghi@yahoo.com (B. Vaseghi), hamidchegini26@gmail.com (H. Chegini)

\section{To cite this article:}

Liela Khobanizad, Mahmood Khobanizad, Behrouz Vaseghi, Hamid Chegini. Implement of Face Recognition in Android Platform by Using Opencvand LBT Algorithm. International Journal of Wireless Communications and Mobile Computing. Vol. 4, No. 2, 2016 , pp. $25-31$. doi: $10.11648 /$ j.wcmc.20160402.13

Received: March 16, 2016; Accepted: March 31, 2016; Published: April 15, 2016

\begin{abstract}
One way of consideration for identifying the human IS recognition of face by portable tools like mobile and tablet. One challenge is low power in portable android tools for face recognition (identification), so GPU must be used in software connection central Graphic processor which has a good function, compared to present processors in today portable android tools. Binary pattern (local) is one of the methods that are used for characteristic production and the image stratification. In this study, it is suggested to use connection and local binary pattern histogram algorithm to use optimum software open CV and using hardware platform android to identify the face.
\end{abstract}

Keywords: Face Recognition, Opencv, Android, LBT Algorithm

\section{Introduction}

Todays, recognition from face has a lot of utilities in commerce and security. The most information is gained from the face identification. To recognize the face, the entrance (input) image is identified and theexist information is also considered. Theexist information in The IB (In formation Bank) contains the known persons image characteristics. Face recognition has a lot of advantages in misdemeanant identification, security systems and other Issues, and so it is taken into account during the recent years. One of the technics for examining to identify the human being is to recognition of faces by portable equipment's.

Recognition is the usual action of human beings' every day job. Increasing of portable tools like computer and mobile causes more consideration to automatic processing on the images including biometric identification, recognition, human interaction and computer and multimedia management. For this reason, searches and developments have been conducting to recognize the faces. Face recognition is prior to other technics like, finger printing and iris. Besides being natural and obscure, the most important advantage of this recognition of face is that the image can be taken or covered from every distance.

Recognition has an important role in photographing, conserving a lot of volume of images in memory or web and increasing the security. One of the examining technics for human identification is face recognition with portable devices. Identification recognition from face image has developed during the recent years and is accompanied by the other devices like phone, mobile and tablet which have intelligent operator system. One the supported smart operation system is android in our age. Android is an open source system based on Linux kernel and Java programing language. Android $3^{\text {rd }}$ part application use Java language and for communication with underlay they can use Java for program. 


\section{Face Recognition}

One of the challenges of face recognition in android potables tools is low of processing ability in GPU, so the software conjecture should be used, because it has a good function. Regarding the exist processors in today android portable tools and the used connector and our kernel process in this study for processing the image in opencv is written in Java language and android compiler can know and use it.

The main applications of face recognition are in table 1 . For each group, the sample applications are also listed. Our application of recognition system of individual identification recognition background is by using the portable android tools which are similar to mobile.

Table 1. Main applications of face recognition.

\begin{tabular}{ll}
\hline $\begin{array}{l}\text { Driving ID card, immigration, national code } \\
\text { passport, the voter's registration, people } \\
\text { recognition and finding their files. }\end{array}$ & Face ID \\
$\begin{array}{l}\text { Car accessibility, ATM and intelligent booth, } \\
\text { computer and online accessibility and } \\
\text { accessibility of online exams. }\end{array}$ & Control access \\
$\begin{array}{l}\text { Flying security system, stadium fan scanning, } \\
\text { computer security, files codding }\end{array}$ & Surveillance \\
$\begin{array}{l}\text { Conserved value security, users } \\
\begin{array}{l}\text { Suspects warning and preventing crime, } \\
\text { prosecution and suspect files survey, } \\
\text { recognition and exploitation of crime face }\end{array}\end{array}$ & Low Enforcement \\
$\begin{array}{l}\text { Faces marking and Images gaining, faces } \\
\text { classification automatic labeling }\end{array}$ & Face data base \\
$\begin{array}{l}\text { Researching based on face, video segregating } \\
\text { based on face identification }\end{array}$ & Multimedia management \\
\begin{tabular}{l} 
Interaction games, Interaction computation \\
\hline
\end{tabular} & $\begin{array}{l}\text { Human and computer } \\
\text { interaction }\end{array}$ \\
\hline
\end{tabular}

Much software has been developed during the recent years to facilitate the processing applications, and the most famous ones are image processing tools boxes in Matlab. However, people who have experienced this tool believe that fulfillment speed of Matlabare annoyer and needs to a powerful processor. It is not an open source either.

\subsection{Definition of Open CV}

Machine vision is one of artificial intelligence that is searching for problem solution which human cannot do it by his/her vision and information analysis. Vision data are prepared in a machine by camera. Different information exploitation of the data and its analysis is the duty of machine vision science. The machine vision can be used everywhere that is necessary and can see instead of human. Using the camera and decision of camera can improve many of the situations that are difficult for human, including individual image (face) identification. Use the machines and camera influences in decreasing of cost fouls and development of system function. The machine vision can be considered one of the middle tools of different sciences. This branch of science has a close relationship with conceptions like image processing and/ or video processing. In many cases it is difficult to distinguish the two cases, however we can call the image processing technic the machine vision science or MVS.

Open source of a vision machine it is an open source library for computer vision that has the following address:

OpenCVhttp://sourceforge.net/projects/opencvlibrary/files/ opencv-android

The program is written in Java and $\mathrm{C}++\mathrm{C}$ and under Linux, windows, Macintosh is applicable. It also is active for means such as Matlab, Ruby and Python.

The aim of opener designing is processing particularly for prompt affairs. It can be used with multichannel processors. One aim of open $\mathrm{CV}$ is preparing a base of computer vision with simple applications, so that the individuals can make relatively complex vision programs. The open CV library includes more than 500 functions about different vision subjects.

Android: simply it is an operating system for mobiles and intelligent receivers which is supported by more than 30 companies. Android is an open source and the developers can write different programs by using SDK Android.

Android programming set or SDK Android including; Android libraries, stimulator, Android documents, and sample files and trading files which help the users to create programs. Now, this SDR is implemented on system with 32 bit or 64 bit which has Linux, windows or OSX mac. The written programs for android are reserved by apk suffix. During the recent years, LBPs display increasingly interest in image processing and computer vision. As a non-parametric technic, LBP, will pluralize the local structures so that compared to Pixel, they are better. The main charter is tics of LBP are:

Tolerance of lighting groovy changes and its simple calculations. Originally, LBP is used for analyzing of suggested contexture and a simple but strong technic for local structures definition.

It is used in applied programs such as face picture analysis, video recovery, environment modeling, vision and optical recovery, moving analysis, air image analysis, biomedical and distance assessment.

Face image analysis based on LBP is one of the most famous and successful application in recent years. It is a research topic and active in computer vision and has a lot of important application such as, interaction of human-computer, biometric recognition, security and surveillance and computer animation. LBP for image display is used in, image identification, image recognition, face situation (position) analysis, demographic classification (sex, race, age ...). The main LBP operator codes the image pixels with decimal and labels them which is called LBPs and then codes the local structure around each pixel. As it is shown in figure (1), the process is as follows:

Patch pixel is neighbored with eight, through fraction of central pixel, which can be compared with 3 ; the values that are strictly negative are coded zero or one for each pixel, B is used. To consider the tissue of different sizes, the next operators will be extended and use the neighborhood with different sizes. 


\begin{tabular}{|c|c|c|}
\hline 6 & 5 & 2 \\
\hline 7 & 6 & 1 \\
\hline 9 & 8 & 7 \\
\hline
\end{tabular}

Pattern $=11110001$

\begin{tabular}{|c|c|c|}
\hline 1 & 0 & 0 \\
\hline 1 & & 0 \\
\hline 1 & 1 & 1 \\
\hline
\end{tabular}

\begin{tabular}{|c|c|c|}
\hline 1 & 2 & 4 \\
\hline 128 & & 8 \\
\hline 64 & 32 & 16 \\
\hline
\end{tabular}

LBP $=1+16+32+64+128=241$

Figure 1. An example of basic operators.
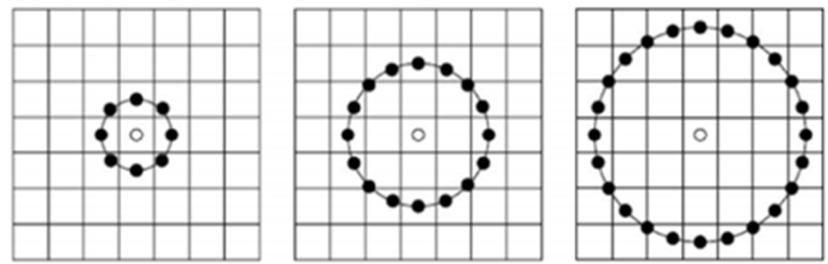

Figure 2. Examples of LBP operator, circular neighbors $(3,24),(8,1),(16,2)$.

The local neighborhood, which $T=t\left(n_{c}, n_{0}, n_{1}, n_{2}, \ldots n_{P-1}\right)$ are a set of sample points with equal distance on the circle, and its center is labeled in pixel and the points that are not in these pixels, by using two ways in patting, are inputted and by this method it is possible to prepare each radius and sampling points near the neighborhood. Figure (2) shows some examples of LBP developed operator. In this figure $\mathrm{P}, \mathrm{R}$ shows the $\mathrm{P}$ neighborhood on the circle with $\mathrm{R}$ radius. The neighbor pixels in LBP are defined on one $L B P_{P, R}\left(x_{c}, y_{c}\right)=$ $\sum_{P=0}^{P-1} s\left(i_{p}-i_{c}\right) 2^{P}$ circle LBP $\left(\mathrm{X}_{\mathrm{c}} \cdot \mathrm{Y}_{\mathrm{c}}\right)$

The main reason for this neighborhood definition is unchangeable evolution and description of tissue and sample. Generally, the result LBP $\left(\mathrm{X}_{\mathrm{c}}, \mathrm{Y}_{\mathrm{c}}\right)$ can be explained as follows.

Where $i_{c}$, and $i_{p}$ are the central pixel grizzly and $p$ is around pixel with $\mathrm{R}$ ridus and $\mathrm{s}(\mathrm{x})$ is defined as follows:

$$
\begin{array}{cr}
x p=x c+R \cos (2 \pi p / P), & s(x)=\{1: x \geq 0 \\
y p=y c+R \sin (2 \pi p / P) . & \{0 ; x<0 .
\end{array}
$$

If the central pixel coordinates are $\left(\mathrm{x}_{\mathrm{c}}, \mathrm{y}_{\mathrm{c}}\right)$ and the neighbor points the circle are $\left(x_{p}, y_{p}\right)$, so by using these formulas, we can conclude them.

$$
L B P_{P, R}^{n}=\min \left\{R O P\left(L B R_{P, R}, i\right) \mid, \quad i=0,1, \ldots, P-1\right\}
$$

If the grizzly pixel value of center is $n_{c}$ and the neighbor pixel grizzly is $n_{p}$ and $i=0 \ldots P-1$, so the $T$ tissue in pixel local neighborhood $\left(\mathrm{x}_{\mathrm{c}}, \mathrm{y}_{\mathrm{c}}\right)$ can be defined as equation shows.

$$
\begin{array}{rl}
\mathrm{T} & =\mathrm{t}\left(\mathrm{n}_{\mathrm{c}}, \mathrm{n}_{0}, \mathrm{n}_{1}, \mathrm{n}_{2}, \ldots, \mathrm{n}_{\mathrm{P}-1}\right) ; \\
\mathrm{T} & =\mathrm{t}\left(\mathrm{n}_{\mathrm{c}}, \mathrm{n}_{0}-\mathrm{n}_{\mathrm{c}}, \mathrm{n}_{1}-\mathrm{n}_{\mathrm{c}}, \mathrm{n}_{2}-\mathrm{n}_{\mathrm{c}}, \ldots, \mathrm{n}_{\mathrm{P}-1}-\mathrm{n}_{\mathrm{c}}\right) ; \quad \text { step } 1 \\
\mathrm{~T} & \mathrm{t}\left(\mathrm{n}_{\mathrm{c}}, \mathrm{n}_{0}-\mathrm{n}_{\mathrm{c}}, \mathrm{n}_{1}-\mathrm{n}_{\mathrm{c}}, \mathrm{n}_{2}-\mathrm{n}_{\mathrm{c}}, \ldots, \mathrm{n}_{\mathrm{P}-1}-\mathrm{n}_{\mathrm{c}}\right) ; \text { step } 2 \\
\mathrm{~T} \approx \mathrm{t}\left(\left(\mathrm{n}_{0}-\mathrm{n}_{\mathrm{c}}\right),\left(-\mathrm{n}_{1}-\mathrm{n}_{\mathrm{c}}\right),\left(\mathrm{n}_{2},-\mathrm{n}_{\mathrm{c}}\right) \ldots\left(\mathrm{n}_{\mathrm{P}-1}-\mathrm{n}_{\mathrm{c}}\right)\right) ; \text { step } 3
\end{array}
$$

\section{$\mathrm{T}$}

By using step 0 . we can access the following stages.

As $t\left(n_{c}\right)$ defines the total brightness of the image and $\left(n_{i}-n_{c}\right)$ is not defended on $n_{c}$, and $t\left(n_{c}\right)$ is not connected to the local image and does not have helpful into for tissue analysis, so we can omit it and the changes between enteral pixel and neighbor pixel is enough.
According to previous definition, LBP base operator is fixed in front of equal transmission of fixed grizzly sizes this process shows that the pixel intensity next to local pixel can be fixed. LBP labels histogram can use as tissue and template descriptor.

The $\operatorname{LBP}_{(\mathrm{P}, \mathrm{R})}, \quad \begin{array}{r}\mathrm{s}(\mathrm{x})=\{1 ; \mathrm{x} \geq 0 \\ \{1 ; \mathrm{x}<0\end{array} 2^{\mathrm{P}}$ produces different output values Which is like different $2^{\mathrm{P}}$ composed by pixel $\mathrm{P}$, and is in the format of neighborhood. In case of image rotation, the round pixels in each neighborhood will move along with the circle and result in different value of LBP. Of course, there is an exception and that is the templates with zero and 1 . To neutralize the rotation, it is suggested to use unchangeable LBP against the rotation.

Where ROR is shift or location change bit by bit $\operatorname{LBP}_{(P, R)}^{r i}$ is unchangeable templates occurrence statistic against the individual rotation which is similar special micro characters. However, it is shown that this operator cannot provide the segregation info necessarily. The reason the number of individual templates occurrence in $\operatorname{LBP}_{(P, R)}^{r i}$ is changeable.

It is proved that the special templates have more info. Compared to the others it is possible to use the subset $2 \mathrm{P}$ for tissue and image template. There template are called invariant ones and are shown as $\operatorname{LBP}_{(P, R)}^{r i}$.

A LBP is called uneventful in case of having two buses and bit to bit transmission from zero to 1 or vice versa. For example, 00000001 (bus zero) and 201110000 (bus) are uneventful, while 411001001 (bus) and 601110000 (bus) are not uneventful. It is observed that uneventful templates next to $(8,1)$ are $90 \%$ of total templates and next to $(16,2)$ in tissue images are $70 \%$ recently Shan and Gritti have surveyed uneventful templates validity and confirmed them. Especially, they used the face situations and Adaboost and their tests showed that by using $\operatorname{LBP}(8,2)$ operator $91 / 1 \%$ of the selected templates are uneventful. The integration of uneventful templates in a small store of LBP operator is less than 2P label. For example, the number of labels with pixel 8 neighborhood for LBP standard is 256 and for $L B P^{U 2}$ is 59.

The aim of f.o., is determine the position and size of face in digital images. Hadid et al, for the first time, used LBP to identify the face. To describe the faces with low resolution and clarification, the LBP operator $(4,1)$ was used for overlapping small area. The SVM was used to discriminate the faces and non-faces. Next, they suggested a hybrid technic to identify unlimited areas. Their technic was studied for main area of skin in an input image to prevent total image scanning.

Then the big strategy to small strategy was used to identify to be face or not to be face in scanned areas. In big step, LBP was used, but in the second one Zhao, Zhang was used.

LBP is also used as preprocessing technic on images. For example, Heusch and others used the LBP as preprocessing step to omit brightness effects. (fig. 3)

One advantage of LBP is that it can make the prompt image face analysis systems structure very attractive. Besides, it can enforce the hardware depended on design to calculate the LBP with high speed. 

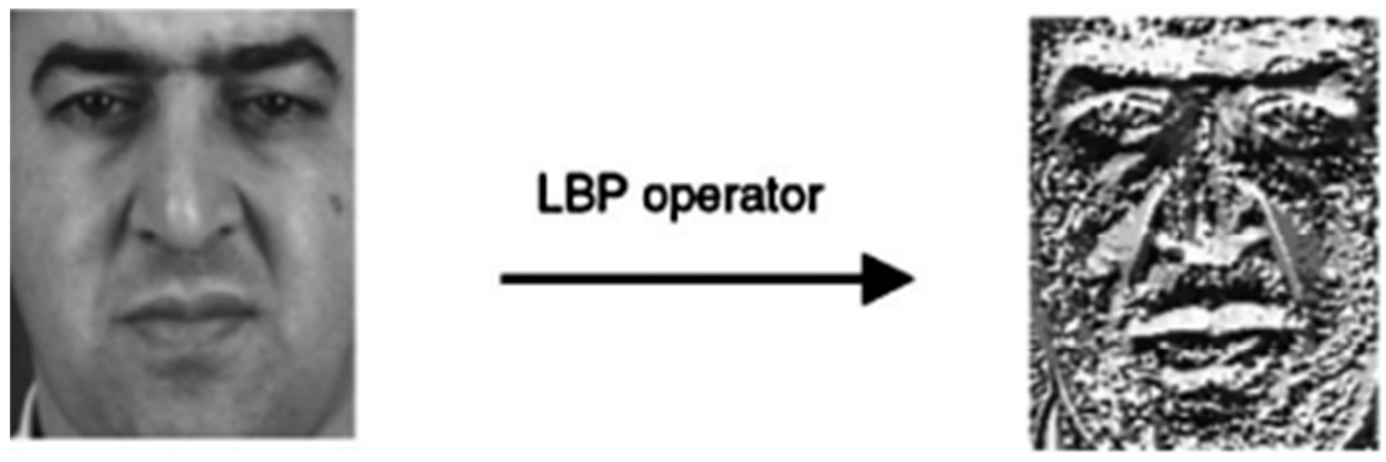

Figure 3. The main image (Left) is processed by LBP (Right).

Hadid et al, by using the F.O. based on LBP, could make a control system. In their system, a camera is on the door to take photos of video frames. In recent years, LBP could attracted many people and it could shows its effect on applied programs, especially face ID analysis, face ID position and demographic classification.

\subsection{Finding}

Today, the word "application" (App) is more usual then "software" for portable devices. The word App has the same meaning as "applied software". The android compilers output can create application with APK suffix, and android operator system can read this suffix. To use this application it should be installed in android tablet or mobile. It is used to face ID. The name of this necessary is manager open CV. If it is not installed, the application (we created) is not practicable. If it is not installed, the software will tell you that you should download this file from Google market and install it. The name of this file is Google play. Google play is a digital distribution service which contains multimedia and has an online market for music, film, book and android games and applications.

Update version of open $\mathrm{CV}$ manager is in the following link:

https://play.google.com/store/apps/details?id=org.opencv.e ngine $\& \mathrm{hl}=\mathrm{en}$

There is another way of installing the prerequisite application, which is defined in the following like:

http://sourceforge.net/projects/opencvlibrary/files/opencvandroid

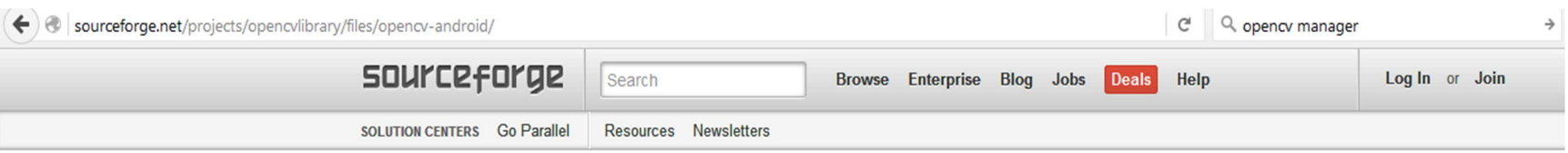

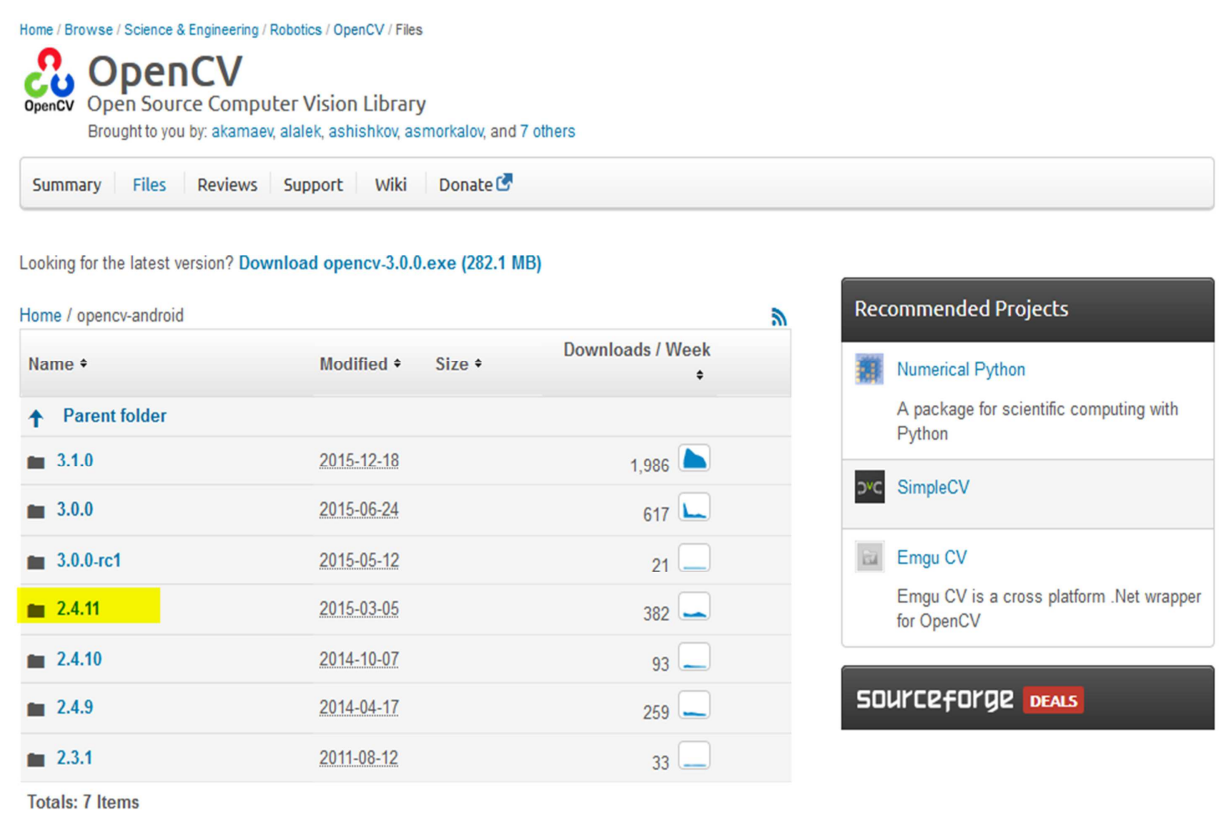

OpenCV: open source computer vision library

Figure 4. Open CV 2.4.11.version. 


\subsection{F.ID Process by Using Produce Application}

After implementation of this Software, we are faced to primary page which is shown in fig. (6).

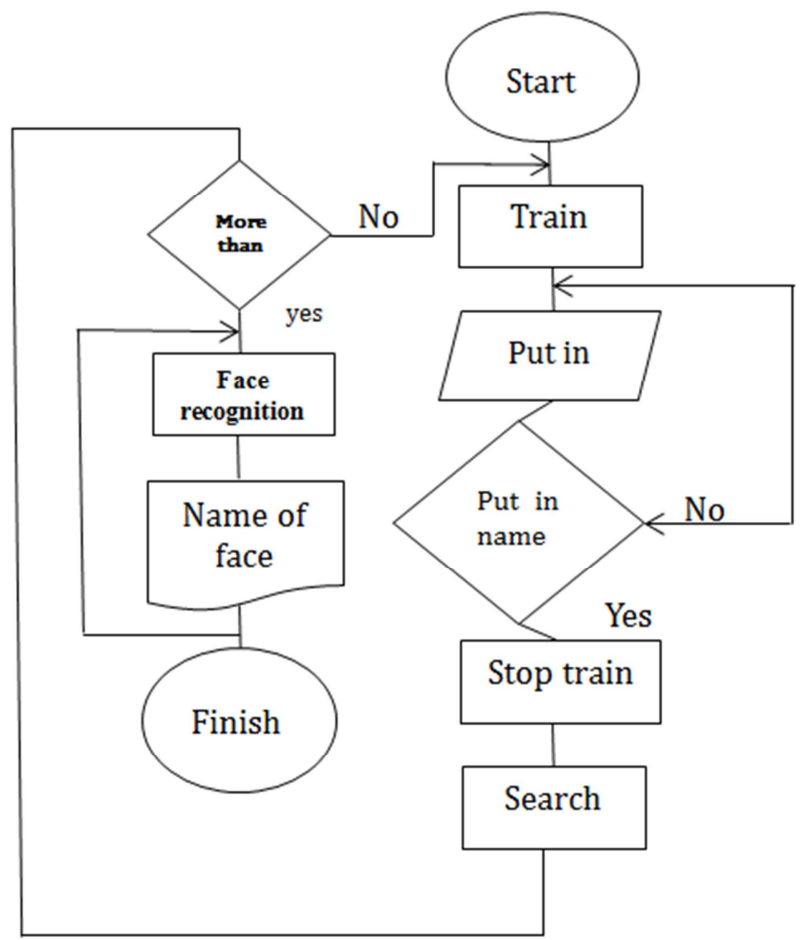

Figure 5. The overall process of implementation of face recognition application chart.

In this page (plane) we are faced to: camera deploys frame, button, and the behind camera change or phone, research button, train button and images display button. The application and buttons process is discussed in the following. At first we introduce the individual's images to the software by touching the train button. We write the name of the image and then touch the record button for server times and then save the names. At the end we touch the stop button.

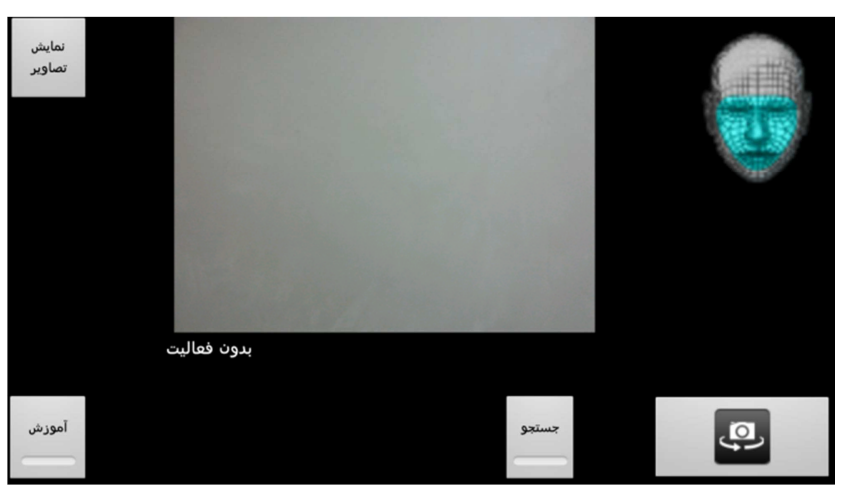

Figure 6. The initial (primary) program page after installing the application.

In this application we need more than one image for recognition. At least, we need two images to train and then by using search button, the application will start recognition. We used binary template histogram algorithm to exploit the characters. If the exploited characteristics from image are homologous with recognized face image, the name of that image will be displayed, infant the application will give us on unknown message (as shown below).

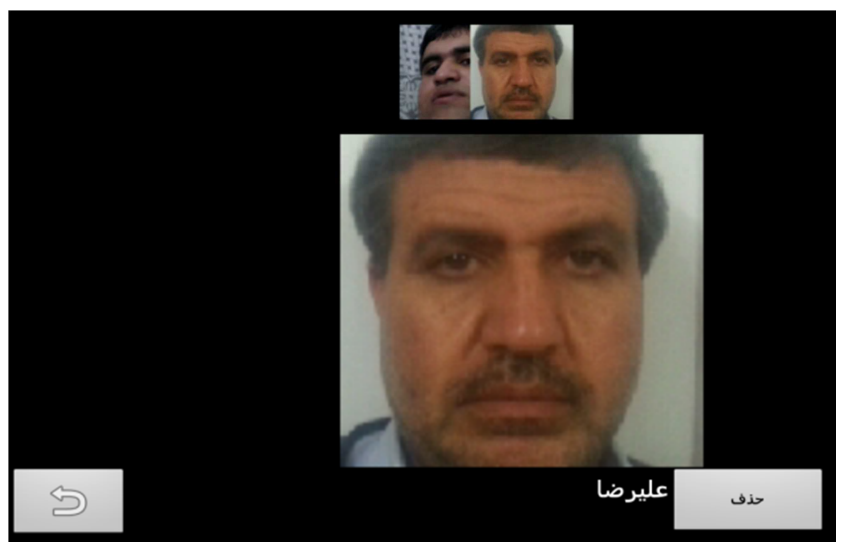

Figure 7. Saving data.

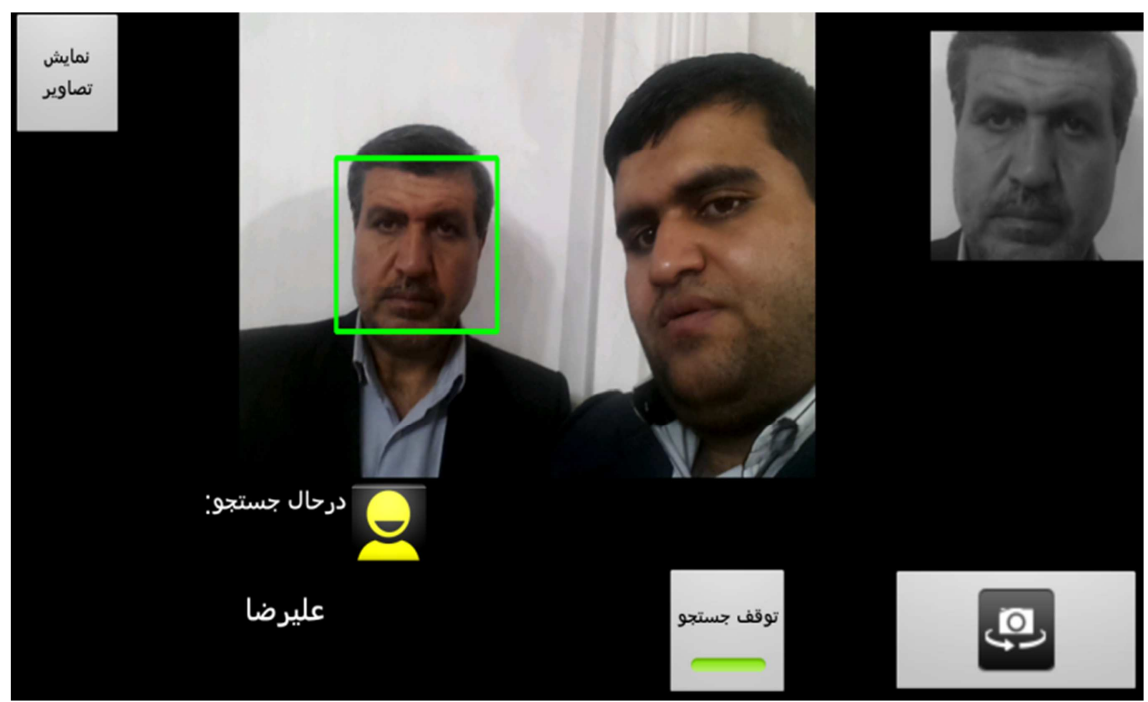

Figure 8. Individuals recognition and displaying their names. 
It is also possible to recognize the face in little light due to using LBPH algorithm. LBPH algorithm has a good function against groovy (monotonous) light and can recognize the individual (as shown in fig. 9).

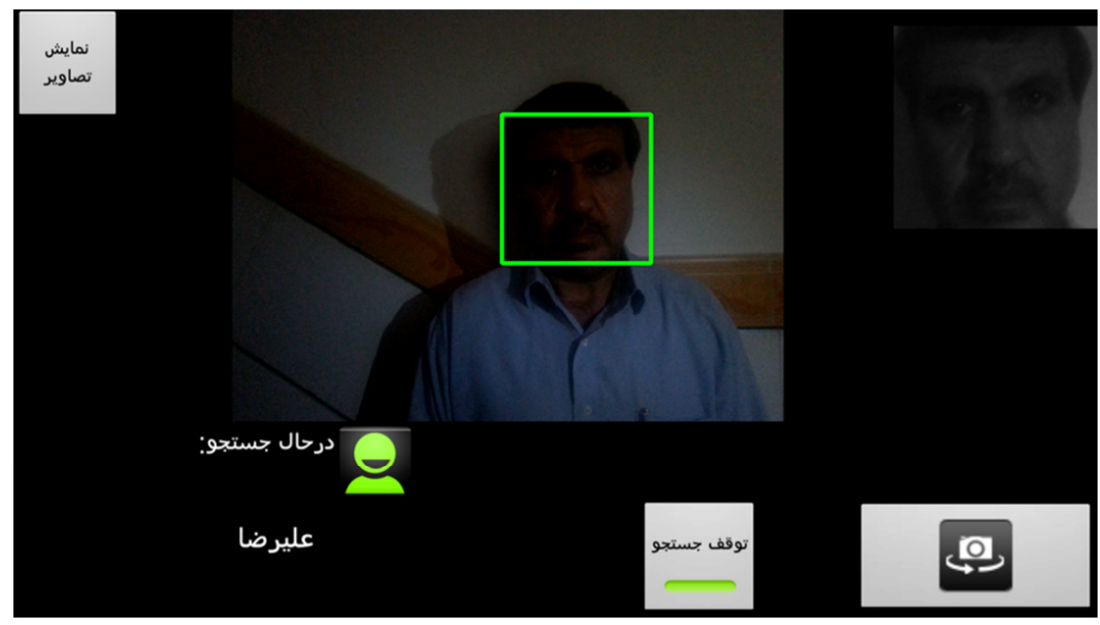

Figure 9. Face ID in little light and displaying the name.

\section{Conclusion}

Face ID is considered for researches connected to machine vision. It is also used in commercial and security applications. The applications in clouding:

Individual's security control, access control, criminal people recognition and interim are between human and computer. Recognition by F. ID is considered by lot of people, due to little necessary contribution of people and agreement. Today, the following device has provided a lot of possibilities for this target: intelligent phone, economical bases, application installation and open android operator system. In this study, we use the open CV as a processing kernel for F.ID, due to hardware limitation in android portable devices and low process ability in graphic processor or GPU. This technic has an appropriate function although there is limitation in today portable devices. The aim of this study is produce an application for F. ID in android platform by using Eclipse open $\mathrm{CV}$ and binary template histogram algorithm. Being info fixed against the light changes, we used a tissue powerful descriptor named $\mathrm{LBPh}$ algorithm. $\mathrm{LBPh}$ descriptor (delineator) is a powerful device to display the local structures and due to its simplicity of calculation, it is used for analyzing the F.ID.

\section{References}

[1] W. Zhao, R. Chellappa, P. J. Phillips and A. Rosenfeld, "Face recognition: A literature survey Acm Computing Surveys (CSUR)”, Vol. 35, no. 4, pp. 399-458, 2003.

[2] P. Belhumeur, J. P. Lanfang, and D. Kriegman, "Eigenfacesvs. fisherfaces: Recognition using class specific linear projection", Pattern Analysis and Machine Intelligence, IEEE Transactions on, Vol. 19, no. 7, pp. 711-720, March. 1997.

[3] M. Sharkas, and M. A. Elenien, "Eigenfaces vs. Fisherfaces vs. ICA for facerecognition; a comparative study," Signal Processing, 2008. ICSP 2008.9thInternational Conference on. IEEE, pp. 914-919, Oct. 2008.
[4] A. Ozdil, and M. M. Ozbilen, "A Survey on Comparison of Face Recognition Algorithms," Application of Information and Communication Technologies (AICT), 2014 IEEE 8th International Conference on, pp. 1-3, Oct. 2014.

[5] X. Lu, "Image Analysis for Face Recognition," http://www.facerec.org/interest.ingpapers/General/ImAna4Fac Rcg_lu.pdf

[6] Gonzalez, Rafael C., and Richard E. Woods, "Digital image processing," (2002).

[7] W. W. Bledsoe. The model method in facial recognition. Technical report pri 15, Panoramic Research, Inc., Palo Alto, California, 1964.

[8] W. W. Bledsoe. Man-machine facial recognition: Report on a largescale experiment. Technical report pri 22, Panoramic Research, Inc,. Palo Alto, California, 1966.

[9] W. W. Bledsoe. Some results on multicategorypatten recognition. Journal of the Association for Computing Machinery, 13(2): 304-316, 1966.

[10] W. W. Bledsoe. Semiautomatic facial recognition. Technical rep ort sri project 6693, Stanford Research Institute, Menlo Park, California, 1968.

[11] W. W. Bledsoe and H. Chan. A man-machine facial recognition systemsome preliminary results. Technical report pri 19a, Panoramic Research, Inc., Palo Alto, California, 1965.

[12] M. Fischler and R. Elschlager. The representation and matching of pictorial structures. IEEE Transactions on Computers, C-22(1):67-92, 1973.

[13] T. J. Stonham. Practical face recognition and verification with wisard. In H. D. Ellis, editor, Aspects of face processing. Kluwer Academic Publishers, 1986.

[14] M. Turk and A. Pentland.Eigenfaces for recognition. Journal of Cognitive Neurosicence, 3(1): 71-86, 1991.

[15] M. McWhertor. "sony spills more ps 3 motion controller details to devs". Kotaku. Gawker Media., June 192009. http://kotaku.com/5297265/sony-spills-more-ps3-motion-contr ollerdetails-to-devs 
[16] Z. Pan, A. G. Rust, and H. Bolouri, "Image Redundancy Reduction for Neural Network Classification Using Discrete Cosine Transforms," Proc. Int. Joint Conf. on Neural Networks, Vol. 3, (Como, Italy), pp. 149-154, 2000.

[17] J. K. Sing, D. K. Basu, M. Nasipuri and M. Kundu, "Face Recognition Using Point Symmetry Distance Based RBF Network," Jour. of Applied Soft Computing, 2005.

[18] M. J. Er, S. Wu, J. Lu and H. L. Toh, "Face Recognition with Radial Basis Function (RBF) Neural Networks," IEEE Trans. on Neural Networks, Vol. 3, No. 3, pp. 697-710, 2002.

[19] Kirby, M., and Sirovich, L, "Application of the Karhunen-Loeve procedure forthe characterization of human faces,” IEEE PAMI, Vol. 12 ,pp. 103-108, (1990).

[20] Sirovich, L., and Kirby, M., "Low-dimensional procedure for thecharacterization of human faces," J. pp. 519-524, (1987). Opt. Soc. Am. A, 4, 3.
[21] H. Anton, Elementary Linear Algebra 5e, John Wiley \& Son Inc, 1987.

[22] M. Turk and A. Pentland, "Face Recognition Using Eigenfaces", Proc. IEEE Conf. on Computer Vision and Pattern Recognition, 1991, pp. 586-591.

[23] Raudys and A. K. Jain. Small sample size effects in statistical pattern recognition: Recommendations for practitioneers. IEEE Transactions on Pattern Analysis and Machine Intelligence 13, 3 (1991), 252-264.

[24] T. Ojala, M. Pietikainen and T. T. Maenpaa .Multiresolution gray-scale and rotation invariant textureclassification with local binary pattern. IEEE Transactionson Pattern Analysis and Machine Intelligence. 24(7): 971-987, 2002.

[25] Gary, Bradski., and Adrian. Kaehler. "Learning Open CV." (2008).

[26] J. F. Dimarzio "Android a programmers guide." (2008). 